\title{
AVALIAÇÃO NACIONAL DO ENSINO MÉDIO E INDÚSTRIA CULTURAL: DA COMPETÊNCIA LEITORA À CRISE DA LEITURA
}

\author{
EVALUACIÓN NACIONAL DE LA ENSEÑANZA MEDIA E INDUSTRIA CULTURAL: \\ DE LA COMPETENCIA LECTORA A LA CRISIS DE LA LECTURA
}

\section{NATIONAL HIGH SCHOOL EVALUATION AND CULTURAL INDUSTRY: FROM READING COMPETENCE TO READING CRISIS}

\author{
Rubiana Brasilio SANTA BÁRBARA ${ }^{1}$ \\ Maria Terezinha Bellanda GALUCH ${ }^{2}$ \\ Rui Bragado SOUSA ${ }^{3}$
}

RESUMO: Mediante a Teoria Crítica da Sociedade, especialmente o conceito de indústria cultural, objetiva-se analisar a competência leitora avaliada pelo Exame Nacional do Ensino Médio (Enem), tomando como exemplo uma questão da prova da área de Linguagens, Códigos e suas Tecnologias (LCT); o texto, os enunciados e as alternativas da questão são objetos dessa análise. A leitura precisa envolver a reflexão crítica, no entanto, o Enem enfatiza uma leitura de mundo mais voltada à identificação de informações explícitas no texto e à resolução de situações-problema. Nesse sentido, as capacidades linguísticas e de comunicação são subjugadas a competências que acabam reduzindo o ato de ler a aspectos da formação que contribuem para reiterar o mundo existente.

PALAVRAS-CHAVE: Indústria cultural. Enem. Leitura. Teoria Crítica da Sociedade.

RESUMEN: Mediante la Teoría Crítica de la Sociedad, especialmente el concepto de industria cultural, se tiene el objetivo de analizar la competencia lectora evaluada por el Examen Nacional de la Enseñanza Media (Enem), teniendo como ejemplo una cuestión de la prueba de Lenguajes, Códigos y sus Tecnologías (LCT); el texto, los enunciados y las alternativas de la cuestión son objetos de este análisis. La lectura necesita involucrar la reflexión crítica, sin embargo, el Enem enfatiza una lectura de mundo más volcada a la identificación de informaciones explicitas en el texto y a la resolución de situaciones-problema. En este sentido, las capacidades lingüísticas y de comunicación son subyugadas a competencias que por fin reducen el acto de leer a aspectos de la formación que contribuyen para reiterar el mundo existente.

PALABRAS CLAVE: Industria cultural. Enem. Lectura. Teoría Crítica de la Sociedad.

\footnotetext{
${ }^{1}$ Universidade Estadual de Maringá (UEM), Maringá - PR - Brasil. Professora do Departamento de Teoria e Prática da Educação. ORCID: https://orcid.org/0000-0002-8674-438X. Lattes: http://lattes.cnpq.br/5525431196863411. E-mail.: rubibras@ hotmail.com

${ }^{2}$ Universidade Estadual de Maringá (UEM), Maringá - PR - Brasil. Professora do Departamento de Teoria e Prática da Educação. ORCID: https://orcid.org/0000-0001-5154-9819. $\quad$ Lattes: http://lattes.cnpq.br/4862416685441579. E-mail: mtbgaluch@uem.br

${ }^{3}$ Universidade Estadual de Maringá (UEM), Maringá - PR - Brasil. Doutorando do Programa de Pós-Graduação em Educação. Lattes: http://lattes.cnpq.br/7224231685249072. E-mail: ruibsousa@ hotmail.com

RIAEE - Revista Ibero-Americana de Estudos em Educação, Araraquara, v. 14, n. esp. 4, p. 1944-1959, dez., 2019. E-ISSN: 1982-5587. DOI: https://doi.org/10.21723/riaee.v14iesp.4.12920 
ABSTRACT: Through the Critical Theory of Society, especially the concept of cultural industry, the objective is to analyze the reading competence assessed by the National High School Evaluation (Enem), taking as an example a question of the Languages, Codes and their Technologies (LCT) evaluation; the text, the statements and the alternatives of the question are objects of this analysis. Reading needs to involve critical reflection, however, Enem emphasizes a world reading more focused on identifying explicit information in the text and solving problem situations. In this sense, language and communication skills are subjugated to competences that eventually reduce the act of reading to aspects of formation that contribute to reiterate the existing world.

KEYWORDS: Cultural industry. Enem. Reading. Critical Theroy of Society.

\section{Introdução}

Em 2018, o Exame Nacional do Ensino Médio (Enem) completou 20 anos. Trata-se de uma avaliação que se fortalece como fruto de reformas e de políticas públicas implementadas a partir da década de 1990, com o intuito de mensurar o desempenho dos estudantes ao término da educação básica, com vistas à melhoria da qualidade do ensino. No ano de 2009, o Enem passou a ser um critério para o acesso ao ensino superior, a cursos técnicos e a programas de bolsas de estudos, como o Programa Universidade para Todos (ProUni) e o Fundo de Financiamento Estudantil (Fies), bem como para o ingresso em institutos de educação superior (IES) de Portugal, que firmaram acordos interinstitucionais de cooperação (BRASIL, 2013) com o Instituto Nacional de Estudos e Pesquisas Educacionais Anísio Teixeira (Inep). Nesse sentido, apresenta-se com a aparência de um mecanismo de democratização e de inclusão.

O Enem exige dos seus participantes a competência leitora denominada também como "arquicompetência", uma vez que abrange todas as áreas avaliadas, incluindo tanto os itens de múltipla escolha da prova, como a redação (MURRIE, 2005, p. 59). O candidato deve fazer uma leitura estratégica e eficiente para chegar à resposta correta e mostrar-se um "leitor do mundo" (BRASIL, 2002, p.14), ou seja, deve saber ler e interpretar textos de linguagens verbal e visual, como mapas, fotos, pinturas, gráficos, dentre outros; deve ser capaz de reconhecer, de selecionar, de organizar e de relacionar. A competência leitora delineada por essas ações aqui mencionadas, na verdade, subjuga-se a um único ato - o de identificar. Apesar de a identificação ser imprescindível no processo de leitura, a compreensão crítica do conteúdo do texto há que ser o objetivo central, todavia a leitura por meio de competências revela a sua crise, que também é a crise da formação e da própria linguagem. 
Nessa perspectiva, a análise da competência leitora avaliada no Enem exige a compreensão da sociedade e das "leis essenciais" (ADORNO, 2008a, p. 86) que a regem, como a exploração, a matematização e a funcionalidade. Por que nos voltarmos à sociedade, se o objeto a ser conhecido são as competências leitoras avaliadas por um exame de larga escala? Porque o Enem expressa o conteúdo da formação que se espera daqueles que concluíram a educação básica; sendo a escola uma instituição situada historicamente, o conteúdo nela ensinado e oficialmente avaliado revela tanto de si, como da sociedade na qual está inserida. Isso significa dizer que "[...] essenciais são as leis objetivas do movimento da sociedade referentes às decisões acerca do destino dos homens [...]” (ADORNO, 2008a, p. 87).

A compreensão dessas leis requer uma teoria que, tal como a sociedade, tem movimento e história. Pela Teoria Crítica da Sociedade, como uma teoria que busca o movimento e as contradições da sociedade e do conhecimento que nela se produz, podemos confrontar conceitos que revelam a não-identificação e as contradições do objeto a ser decifrado. Na relação entre indústria cultural e linguagem, buscamos elementos para sustentar nossa reflexão sobre a tomada de consciência - a autorreflexão crítica sobre a formação - e, portanto, sobre a possibilidade de resistência e de formação para a não-identidade. Isso significa o confronto, cujas brechas contêm elementos emancipatórios. Dito isso, resta esclarecer que no confronto entre indústria cultural e linguagem, esperamos encontrar as leis objetivas expressas em fenômenos sociais e, assim, entendermos as competências leitoras avaliadas pelo Enem na sua relação com as leis objetivas - não estáticas - da sociedade industrial desenvolvida, também ela em movimento.

Não podemos negar a relevância de avaliações em larga escala, porém quando a preocupação maior é formar para o aluno obter boa pontuação nesse exame, sua função passa a ser a de fortalecer a sociedade que classifica e exclui. São formas do exercício da integração total e de a democrática não se desenvolver tal como foi prometida. O Enem, ao se apresentar como um direito que substitui o direito à educação, é também ele antidemocrático.

\section{Indústria cultural e a linguagem das competências}

O termo Indústria Cultural foi cunhado em 1947 por Adorno e Horkheimer, na obra Indústria cultural: o esclarecimento como mistificação das massas. Os autores evidenciam as diferenças entre a indústria cultural e a cultura de massa. São conceitos que, postos lado a lado, permitem identificar que não há uma cultura para a elite burguesa; tampouco essa se opõe à 
cultura produzida pelo povo ou para o povo, mas que existe uma única cultura no mundo burguês (ADORNO; HORKHEIMER, 1985).

A indústria cultural fortalece a racionalização e submete o indivíduo à sociedade alicerçada na liberdade controlada, ou seja, na falsa liberdade, sociedade esta que se caracterizada pela necessidade de uns exercerem a força e a dominação sobre os outros, que não se reproduz sem a permanência da exclusão, bem como que cria necessidades e formas de satisfazê-las. Marcuse (1973, p. 26) afirma que "a intensidade, a satisfação e até o caráter das necessidades humanas, acima do nível biológico, tornam-se precondicionados". Na sociedade da troca, tudo se transforma em mercadoria, inclusive a cultura, que se coloca em exposição, como objetos a serem cobiçados e comprados, independentemente do valor a ser pago por eles. Subjugada à indústria cultural, assim como a arte, a cultura perde sua aura, destituindo-se do seu valor imaterial.

A indústria cultural não somente faz parte de uma sociedade administrada, como a constitui e também forma o corpo, a mente, a alma e o coração do indivíduo. Na sociedade atual a "[...] manipulação das necessidades por interesses adquiridos" impede o surgimento de uma oposição ao todo (MARCUSE, 1973, p. 25). O ajustamento à realidade tem sua força na organização da sociedade pela indústria cultural, que faz com que o conhecimento reproduza o existente, fortalecendo a adaptação e o pseudoconhecimento; em vez de a realidade ser negada, experimenta-se a sua exaltação. A consciência é moldada e condicionada por valores econômicos. Adorno e Horkheimer (1985) explicam a contradição do capitalismo tardio que promete uma vida boa para aqueles que atendem à sociedade posta. Para os autores, é uma cultura com padrões que se repetem formando uma estética comum, voltada ao consumo.

Há que se ter claro que a indústria cultural, como explicam Galuch e Crochík (2018, p. 25), "é um sistema, [e] não deve ser identificada com os meios de comunicação de massa televisão, cinema, rádio, jornal -, nem com os produtos desses meios - programas televisivos, filmes [...]". É um sistema, pois o que ocorre num meio de comunicação reverbera em outros, um encadeamento sucessivo de imagens, músicas, textos que se expandem e chegam até as pessoas de várias maneiras. Uma das maneiras dessa reverberação é pela educação, cujo exemplo de como ela representa os mesmos conteúdos e formas que reproduzem a realidade posta podemos encontrar na avaliação. Ao mesmo tempo que o indivíduo se torna igual perante o consumo, a indústria cultural, contraditoriamente, aplica a sua outra face para se fortalecer, quando cada um deve se comportar de acordo com o seu "level", ou seja nível "[...] previamente caracterizado por certos sinais, e escolher a categoria dos produtos de massa fabricada para seu tipo" (ADORNO; HORKHEIMER, 1985, p. 116). Os grupos de pessoas se tornam tipos de RIAEE - Revista Ibero-Americana de Estudos em Educação, Araraquara, v. 14, n. esp. 4, p. 1944-1959, dez., 2019. E-ISSN: 1982-5587. DOI: https://doi.org/10.21723/riaee.v14iesp.4.12920 
classes - A, B ou C - que são destacadas em um mapa utilizado pelo marketing que identifica quais são os rendimentos dos consumidores, o que facilita incutir a cada um aquilo que merece. Essa classificação remete ao fato de o Enem ter suas questões divididas em fáceis, médias e difíceis, o que facilita o controle sobre o participante de acordo com o seu nível de desempenho, ou seja, essa forma ratifica as diferenças entre a classificação dos participantes que, “democraticamente", os encaminhará às universidades, aos cursos técnicos, sendo, também, um critério para a concessão de bolsas de estudos.

Ter consciência de como a indústria cultural atua sobre os sujeitos permite-nos pensar a relação sujeito e objeto, assim como entender que existe a possibilidade da dignidade humana, mas é o seu contrário que se estabelece em um sistema que instaura a harmonia no embrutecimento e na funcionalidade; que impede a reflexão e tudo se volta à aceitação. Essa reflexão nos remete ao princípio da razão iluminista e nos ajuda a compreender o porquê de a liberdade do indivíduo subjugar-se às demandas da sociedade. Marcuse (1999, p. 75) explica que o indivíduo foi convertido na "[...] unidade fundamental bem como no fim da sociedade [...]" pelos representantes da revolução burguesa. Ele sustentava os valores contrários à sociedade vigente e era considerado detentor de padrões e de valores voltados para o desenvolvimento da consciência e das habilidades humanas. Esses padrões e valores eram a verdade da existência, tanto individual quanto social. $\mathrm{O}$ indivíduo da sociedade burguesa era capaz de refletir sobre essas verdades, era capaz de transformá-las em realidade, porque tinha liberdade de pensamento.

A razão, cujo princípio era o ideal de libertação, acabou por ser despojada do seu potencial crítico, tornando-se ela mesma o seu contrário. Seu ofuscamento representou a perda do ideal revolucionário do iluminismo. De uma razão emancipatória, passou-se, gradativamente, para uma razão instrumental, na sociedade que, devido sua forma de organização e de produção, tornou-se unidimensional. Nessa sociedade, a razão assume uma função instrumental (HORKHEIMER, 2002). O pensamento passa, então, a ser apresentado sob formas mensuráveis, quantificáveis, posto a serviço do progresso social, em vez de se colocar a serviço dos próprios homens. Nesse contexto, ofusca-se a dinâmica do poder, portanto é necessário conhecer os mecanismos que submetem as pessoas cotidianamente a um processo de moldagem de sentidos em que "[...] a racionalidade técnica [...] é a racionalidade da própria dominação [...]", ou seja, a irracionalidade (ADORNO; HORKHEIMER, 1985, p. 114).

Essa reflexão sobre a razão e sobre o porquê de a liberdade do indivíduo ser objetivada e mediada, leva-nos ao entendimento de como isso ocorre nas diferentes instâncias da sociedade, sendo a educação e o Enem uma delas. Assim, ao partirmos do pressuposto de que RIAEE - Revista Ibero-Americana de Estudos em Educação, Araraquara, v. 14, n. esp. 4, p. 1944-1959, dez., 2019. E-ISSN: 1982-5587. DOI: https://doi.org/10.21723/riaee.v14iesp.4.12920 
o Enem é uma das formas racionalizadas do pensamento, uma forma de controle, entendemos que a dominação aparece, inclusive, na própria hierarquia que a avaliação promove. $\mathrm{O}$ discurso está na formação de competências que capacitem o indivíduo a ser autônomo, a saber como proceder em situações de pressão, o que, contraditoriamente, significa ser um sujeito bem adaptado para reproduzir a sociedade da dominação.

Nesse sentido, destacamos que à educação cabe resistir a essas imposições, entendendo que o esclarecimento, por si, não é capaz de superar a sociedade da exploração; mas, está nele a possibilidade de lançar luz sobre o que, nessa sociedade, impede o seu potencial de liberdade. A proposta da fundamentação metodológica do Exame afirma, que ao leitor cabe ultrapassar os limites da decifração linguística, enfatizando ser necessário ler e interpretar textos com diversas linguagens verbais e visuais, bem como, os enunciados, ou seja, “[...] identificando e selecionando informações centrais e periféricas; inferindo informações, temas, assuntos, contextos; justificando a adequação da interpretação; compreendendo os elementos implícitos de construção do texto [...]" (MURRIE, 2005, p. 59).

É fundamental entendermos que essas ações que prometem ultrapassar a decifração linguística, bem como o papel essencial atribuído à leitura pelo Enem apresentam seus limites no fato de desconsiderar o conteúdo veiculado no texto da questão cuja resposta, muitas vezes, está no próprio enunciado, exigindo do leitor apenas a busca por informações explícitas. Nesse sentido, qual a relação entre sujeito e objeto, quando se pretende "dominar a linguagem" como um fim em si mesmo?

A linguística, como afirma Marcuse (1973, p. 163), vem com o propósito de livrar o pensamento e a palavra de "fantasmas", portanto, da metafísica; vem, ainda, com o objetivo de corrigir o comportamento anormal, tanto do pensamento, quanto da palavra, retirando as ilusões, as extravagâncias e as obscuridades. A discussão de Marcuse apresenta elementos mediante os quais entendemos que, em algumas questões do Enem, o leitor não precisa compreender a mensagem do texto, pois nelas o conteúdo é sempre semelhante, apresentandose como um limite para a própria linguagem.

O esforço, fundamental para o conhecimento, aparta-se do sujeito para fixar-se no objeto que se deixa facilmente ser pseudoconhecido, dando a impressão de que há interação entre o leitor e o texto. Da mesma forma, ocorre em questões que apresentam textos importantes da literatura, mas que são colocados em segundo plano quando o que se pede é tão somente a identificação, reiterando a cultura sob a perspectiva da indústria cultural, que leva os sujeitos à identificação daquilo que deve ser consumido. A arte, a religião e a ciência, que serviriam para a liberdade porque significavam o meio pelo qual os homens faziam a crítica à sociedade, RIAEE - Revista Ibero-Americana de Estudos em Educação, Araraquara, v. 14, n. esp. 4, p. 1944-1959, dez., 2019. E-ISSN: $1982-5587$. 
tornam-se produtos da indústria cultural e mecanismos de reprodução da sociedade, subjugando-se e prendendo-se, a exemplo, em uma avaliação em larga escala.

Treinam-se os olhos, os ouvidos, as mãos, os gostos, o toque e também a alma. É possível imaginar como o filme termina, por isso a imaginação já não é ela mesma; é possível saber quem merece a recompensa e quem merece ser punido; prevalecem as mesmas canções, os mesmos artistas e o mesmo conteúdo disfarçado na aparência; os detalhes, os atores e os personagens podem ser substituídos; já o conteúdo deve ser mantido, para ser reconhecido, portanto não é conteúdo, mas forma. São “[...] clichês prontos para serem empregados arbitrariamente aqui e ali e completamente definidos pela finalidade que lhes cabe no esquema [...]" (ADORNO; HORKHEIMER, 1985, p. 118).

A linguagem é um dos mecanismos que contribuem e fortalecem o sistema da indústria cultural por meio da padronização. Podemos dizer, portanto, que as novas qualidades humanas são "um modo difundido de pensamento" que estabelece padrões de julgamentos e de atitudes. As qualidades referentes à percepção e ao conhecimento se tornam competências e treinamentos ordenados em uma atuação padronizada. Como diz o próprio autor, são mudanças ligadas à alma (MARCURSE, 2001, p. 44). A alma é indispensável para o controle dos indivíduos, ela é uma das forças mobilizadas para contribuir com a coesão social. É na cultura da alma que são absorvidas as qualidades humanas como o talento, a polivalência, a solidariedade, a bondade, a competência, a empregabilidade, a alegria, a verdade, e tantos outros termos da atualidade. São anseios dotados de uma caracterização afirmativa que se tornam qualidades que engrandecem o indivíduo, que demonstram superioridade àqueles que as possuem.

Com a crescente racionalização técnica e a linguagem nesse contexto, reduzem-se as interações concretas, já que tudo é virtual, flexível e global, ao mesmo tempo que essa forma de relação entre os sujeitos e a linguagem que a acompanha, apresentam discursos inovadores e alternativas utópicas (MARCUSE, 2001). As formas da razão instrumental que configuram a linguagem no capitalismo tardio prevalecem. Um exemplo está no que se tornou o ato de ler, por exemplo, nas questões do Enem. Nele, o participante precisa ter a competência leitora, que não significa compreender o texto em sua totalidade, tampouco perceber que o sentido da palavra se perde na forma como é apresentado, ou seja, não precisa necessariamente a compreensão da palavra e do próprio texto; o foco é dado à organização e à identificação, etapas importantes do processo de leitura, todavia insuficientes para um leitor que se quer consciente, que deve entender a relação entre a forma do texto e o seu conteúdo, bem como perceber uma linguagem envolvida pela comunicação que indica o que se deve ler. 
Os mecanismos sociais consomem a linguagem; a expressão que um dia lhe pertenceu agora segue as direções dominantes intensificada pela indústria cultural. Os textos literários são submetidos a uma "previsão automática" meticulosa pelo seu produtor, editor ou redator. Para Adorno e Horkheimer (1985, p. 13), tornar suas funções supérfluas seria a ambição do sistema educacional, pois a depreciação do pensamento teórico organiza o percurso para a alienação política. Mesmo as pessoas, de acordo com os autores, que ainda não se renderam ao pensamento dominante e alienador são privadas das possibilidades de oposição devido aos mecanismos de censura. Evita-se o pensamento próprio do espectador e o esforço pessoal; atrofiam-se a imaginação, a espontaneidade e a atividade intelectual do indivíduo. O processo do pensamento é alterado para o modo automático, não pelo conhecimento, mas pela sua negação, já que se converte em procedimento.

A separação das funções da própria linguagem exprime a dominação do homem pelo homem; nesse sentido, as formas de pensamento se aproximam da linguagem científica e põem fim à metafísica; esvaziam-se as ideias e, com isso, a possibilidade de expressão e de autorreflexão crítica que “[...] nada mais era senão a hipostasiação da dureza e da exclusividade que os conceitos tinham que assumir onde quer que a linguagem reunisse a comunidade dos dominantes para o exercício do comando" (ADORNO; HORKHEIMER, 1985, p. 35). Nesse sentido, analisar criticamente a competência leitora avaliada pelo Enem é compreender a linguagem subjugada à linguagem unidimensional sob os ditames da indústria cultural.

\section{Da competência leitora à crise da leitura}

Como indicado em momentos anteriores neste texto, o Enem é uma avaliação que exige do leitor a capacidade de identificar informações no texto, que requer o saber traçar a diferença entre a linguagem formal e a não formal. Este aspecto pode ser melhor explicado com a seguinte ideia de Adorno (2008b, p. 97): “[...] só o verdadeiramente alienado, a palavra marcada pelo comércio, a toca como familiar. [...]. Quem quiser escapar-lhe deve considerar todo conselho a cuidar da comunicação como traição ao comunicado".

Para Adorno e Horkheimer (1985, p. 48), “[...] os instrumentos de dominação destinados a alcançar a todos - a linguagem, as armas e por fim as máquinas, devem se deixar alcançar por todos [...]”. Isso é claramente observável na avaliação. Geralmente, o significado da linguagem é enfatizado, seja ela a do povo ou a das máquinas, mas a identificação para a comunicação sem se atentar para o conteúdo da comunicação. Isso nos faz pensar que a razão que deveria estar 
na linguagem se converte em irracionalidade e usa a própria linguagem para fins de controle. Dessa forma, o conhecimento se presta à pseudoformação. Para Adorno (1995a, p. 64-65), a linguagem é forma de "expressão rigorosa do objeto", o que difere, por exemplo, da habilidade 26 do Enem (BRASIL, 2013, p. 19) que orienta a necessidade de "relacionar as variedades linguísticas a situações específicas de usos social".

As diferentes formas da linguagem dizem respeito à expressão social, contudo há que se atentar para a simplificação da linguagem promovida tanto pelo interesse do mercado, como por interesses políticos. Na linguagem, é preciso ficar em evidência o direito de o indivíduo ir além do que é de uso do seu cotidiano, para conhecer as formas de falar e de pensar por meio de "[...] termos que são significativos, racionais e válidos precisamente pelo fato de serem outros termos [...]” (MARCUSE, 1973, p. 170). Não são a linguagem culta ou a não culta que estão em jogo, mas a necessidade de se pensar que as duas formas de linguagem contêm a irracionalidade acerca da qual é preciso que se tome ciência. Não se trata de focar as nuances da fala, mas analisar e compreender o contexto em que as pessoas não apenas falam, mas agem e, portanto, significam sua forma de falar; desse modo, também significam a palavra. Esse modo de pensar o contexto em que o particular expressa o universal, e vice-versa, é deixado de lado quando a análise se pauta pelo positivismo, diz Marcuse (1973). No Enem, isso significa perder o conteúdo em favor de diferentes formas de linguagem.

Para a comunicação irracional, é fundamental que o que está para além do imediato, do uso comum, não atrapalhe o "universo ordinário da locução". A análise crítica requer que os termos filosóficos sejam diferentes dos termos ordinários; que tais termos esclareçam e tragam à tona o fato de os indivíduos serem impelidos a determinadas ações, a determinadas nuances da linguagem, porque guiados pela sociedade na qual, para viver, são submetidos a necessidades criadas. O indivíduo é impelido a “[...] identificar a 'coisa' (incluindo a própria pessoa, sua mente, seus sentimentos) com as suas funções. Como sabemos disso? Vendo televisão, ouvindo rádio, lendo jornais e revistas, falando com os demais" (MARCUSE, 1973, p. 182).

A fala tanto é expressão do indivíduo, como de um contexto em que outros o fazem falar como falam. Os conhecimentos, os sentimentos e os desejos dos indivíduos são também os de outros que empregam as palavras, que lhes ditam a economia, a política, o consumo e a propaganda. “Ao descreverem 'por si mesmas' a situação política, [...] elas (e o termo 'elas' também inclui a nós os intelectuais que conhecemos a situação e a criticamos) descrevem o que o 'seu' meio de comunicação de massa lhes diz [...]” (MARCUSE, 1973, p. 182, grifo do autor).

As palavras usadas não condizem apenas com a língua materna, como identidade, como marcas linguísticas que singularizam as variedades linguísticas sociais, regionais e de registro, RIAEE - Revista Ibero-Americana de Estudos em Educação, Araraquara, v. 14, n. esp. 4, p. 1944-1959, dez., 2019. E-ISSN: 1982-5587. 
como requerido na competência de área 8 da Prova de Linguagens, Códigos e suas Tecnologias do Enem (BRASIL, 2013, p. 20), mas condizem com palavras de anúncios, da política, do cinema. A padronização e a estereotipia permitem que a comunicação seja globalizada, perdendo a cultura que poderia, por exemplo, diferenciar o amor, o ódio e a alegria - os sentimentos são estandardizados nas telas. Marcuse diz: “[...] tem necessariamente de ser assim, porque a linguagem nada tem de particular e pessoal, ou, antes, porque o particular e pessoal é mediado pelo material linguístico disponível, que é material social [...]” (MARCUSE, 1973, p. 183).

Ainda para Marcuse (1973), a análise linguística que se resume à exatidão empírica, examinando situações cotidianas e superficiais, desconsiderando o estado das coisas que enredam o indivíduo, submete-se à restrição de uma locução decepcionante. Revela-se, assim, a linguagem unidimensional que cala a história da palavra; não há espaço para significados diferentes, tampouco àqueles que se conflitam. Eles são mantidos separados, para que o leitor não os interprete.

Ao se referir sobre a instrumentalização da razão, Horkheimer explica que quanto mais o pensamento se torna automático, instrumentalizado, menos terá significado próprio. Nisso a linguagem desempenha papel fundamental porque ela se transformou em um instrumento para o "aparelho de produção da sociedade moderna", de modo que a sentença deve equivaler a uma operação sem sentido (HORKHEIMER, 2002, p. 27). Em primeiro plano, está a função da palavra ou a atuação dela no mundo das coisas, quer dizer, a função supera o significado.

Nesse sentido, a linguagem administrada é um instrumento para a orientação das massas; serve para estocar e comunicar. Como explica o autor, ela se converte em seu estágio mágico, cuja palavra tem força e pode destruir a sociedade, responsabilizando aquele que fala; por isso, não há diferença entre pensamento e ação - o pensamento é um ato. O indivíduo é repreendido pelo que diz ou pelo que não diz; é classificado e rotulado, sendo que valores que o tornam humano, tais como justiça, igualdade, felicidade e tolerância, perdem suas raízes intelectuais, tornando-se objetivos e fins, “[...] mas não há mais uma força racional autorizada para avaliá-los e ligá-los a uma realidade objetiva [...]” (HORKHEIMER, 2002, p. 27).

Ao entendermos a unidimensionalidade do pensamento por meio da linguagem, percebemos que os leitores não são passivos em relação aos conteúdos avaliados; todavia esse 'leitor do mundo’ é direcionado a enxergar aspectos já definidos, ou seja, há uma pré-seleção, uma pré-atenção; ele é treinado para agir mediante competências e habilidades administradas. Também não podemos nos esquecer de que o leitor, na condição de participante de uma 
avaliação que o classifica, pode ocupar-se menos com o conteúdo veiculado e mais com a necessidade de marcar a opção correta para a obtenção de boa pontuação.

Um exemplo do que ora mencionamos, pode ser encontrado em uma questão do Enem de 2009, que avalia a competência de área 8, referente à identificação da língua, buscando “compreender a língua portuguesa como língua materna, geradora de significação e integradora da organização do mundo e da própria identidade". A habilidade relacionada é a H 27, ou seja, a que diz respeito ao "reconhecer os usos da norma padrão da língua portuguesa nas diferentes situações de comunicação" (BRASIL, 2013, p. 20). Apesar de estarem ligadas à identificação e ao uso social e de comunicação (aspectos importantes da linguagem), não são suficientes para levar o leitor à reflexão.

Figura 1 - Questão n. ${ }^{\circ} 125$ do Enem de 2009.

\begin{tabular}{|c|}
\hline $\begin{array}{l}\text { CARA, JE, tipo Assim, } \\
\text { O SEU FICtho Escrever } \\
\text { Na parte superior do anúncio, há um comentário escrito à mão que aborda a questão das atividades } \\
\text { linguísticas e sua relação com as modalidades oral e escrita da língua. Esse comentário deixa } \\
\text { evidente uma posição crítica quanto a usos que se fazem da linguagem, enfatizando ser necessário } \\
\text { A - implementar a fala, tendo em vista maior desenvoltura, naturalidade e segurança no uso da } \\
\text { língua. } \\
\text { B - conhecer gêneros mais formais da modalidade oral para a obtenção de clareza na comunicação } \\
\text { oral e escrita. } \\
\text { C - dominar as diferentes variedades do registro oral da língua portuguesa para escrever com } \\
\text { adequação, eficiência e correção. } \\
\text { D - empregar vocabulário adequado e usar regras da norma padrão da língua em se tratando da } \\
\text { modalidade escrita. } \\
\text { E - utilizar recursos mais expressivos e menos desgastados da variedade padrão da língua para se } \\
\text { expressar com alguma segurança e sucesso. }\end{array}$ \\
\hline
\end{tabular}

Fonte: Brasil (2009, p. 14).

A questão apresenta um texto com um aviso cuja linguagem é informal, geralmente usada por adolescentes e jovens. Em relação ao conteúdo que se pretende avaliar, sob a luz da competência 8, podemos afirmar que o objetivo da questão não é avaliar o conhecimento sobre a língua escrita, inclusive o leitor não precisa ler o anúncio localizado abaixo da anotação para relacionar o seu conteúdo ao comentário registrado à mão. Mediante a linguagem não formal, passa-se a mensagem da necessidade de se escrever bem; utilizando o recurso da RIAEE - Revista Ibero-Americana de Estudos em Educação, Araraquara, v. 14, n. esp. 4, p. 1944-1959, dez., 2019. E-ISSN: 1982-5587. DOI: https://doi.org/10.21723/riaee.v14iesp.4.12920 
metalinguagem, usa-se a linguagem para falar sobre a própria linguagem. A metalinguagem, nesse texto que evidencia a escrita de norma não culta para falar sobre a necessidade de se escrever corretamente, pode ser considerada pertencente ao "universo da locução no qual os opostos são reconciliados [...] essa união se expressa na suave conjunção linguística de partes da locução em conflito". Embora Marcuse (1973, p. 96-97) se refira a palavras e a expressões, o texto contempla essa mesma configuração: "a unificação dos opostos que caracteriza o estilo comercial e político é uma das muitas formas pelas quais a locução e a comunicação se tornam imunes à expressão de protesto e recusa". Por isso, a discrepância de que - nesta questão e em tantas outras - o Enem avalia, somente a linguagem informal.

Em Sopa de pedras, Adorno (2008b, p. 97) afirma que “[...] somente a fala que subsume em si a escrita libera a fala humana da mentira de que já seja humana". Essa ideia é fundamental para compreendemos que a fala é controlada. Quando a burguesia usa a linguagem para contrapor as determinações de seus senhores, traz a independência e a autodisciplina, mas a linguagem dos subalternos é determinada, esvaindo-se com ela também a justiça. As desigualdades culturais implicam diretamente a formação. Interessante como Adorno (2008b) se refere ao fato de a pobreza material repercutir na própria linguagem e, por meio dela, aquele a quem é negada a riqueza social macular, aviltar a cultura (linguagem culta), ou seja, o pobre "mata" a linguagem no modo como fala, como se, assim, conseguisse afrontar a morte do seu corpo imposto pela impossibilidade de nutri-lo com o pão material que, apesar de participar da sua produção, é-lhe negado. “[...] A fala proletária é ditada pela fome. O pobre mastiga as palavras para saciar-se nelas [...] ele enche a boca que não tem o que morder. Destarte ele se vinga na linguagem [...]" (ADORNO, 2008b, p. 98).

$\mathrm{O}$ texto escrito à mão é, provavelmente, dirigido a um receptor adulto, um pai ou uma mãe, levando-se em conta a possibilidade da inferência a ser feita por meio da expressão 'seu filho'. A gíria 'cara' é empregada a pessoas independentemente do gênero, portanto, pai, mãe ou responsável. A expressão "tá ferrado" funciona como um aviso que responsabiliza quem não sabe escrever corretamente, por exemplo, pelo fato de não conseguir um emprego. Embora possa funcionar como uma ameaça, não há elementos explícitos para o leitor perceber isso.

A decodificação é a capacidade mais avaliada; mais uma vez, os fatos imediatos sobrepõem-se aos seus fatores; a locução funcional se põe a serviço da subordinação. Como ressalta Marcuse (1973, p. 102), é uma “[...] linguagem irreconciliavelmente anticrítica e antidialética. Nela, a racionalidade operacional e behaviorista absorve os elementos transcendentes, negativos e de oposição da Razão".

Conforme exposto na Figura 1, na Prova do Enem, o enunciado da questão determina: RIAEE - Revista Ibero-Americana de Estudos em Educação, Araraquara, v. 14, n. esp. 4, p. 1944-1959, dez., 2019. E-ISSN: 1982-5587. 
Na parte superior do anúncio, há um comentário escrito à mão que aborda a questão das atividades linguísticas e sua relação com as modalidades oral e escrita da língua. Esse comentário deixa evidente uma posição crítica quanto a usos que se fazem da linguagem, enfatizando ser necessário (BRASIL, 2009, p. 14).

O enunciado é utilizado para que o leitor o complete com uma das alternativas que enfatizam o uso da linguagem. Que posição crítica seria possível com o enunciado apresentado? Os olhos do leitor, a partir desse enunciado, são direcionados ao comentário de um anúncio cuja imagem, inclusive, é ilegível. O texto cumpre apenas o papel de se referir a um contexto. Fica evidente que a frase "cara, se, tipo assim, o seu filho escrever como fala ele tá ferrado", seria familiar aos participantes, promovendo neles a sensação de o texto fazer parte da sua vida real.

No enunciado não há elementos para que o leitor reflita sobre a mensagem; ele permite apenas a sua decodificação. $\mathrm{O}$ enunciado funciona como um aviso aos jovens em relação ao uso que eles fazem da linguagem, nesse caso, o da língua escrita, fechando o pensamento mediante a seguinte menção: "enfatizando ser necessário" saber que é preciso escrever corretamente. Em relação às alternativas, ao escolher a resposta considerada correta - a D -, o leitor deve compreender que se trata de um manuscrito que critica a forma de os jovens escreverem como falam. Novamente, a norma padrão da escrita é exaltada como uma adequação necessária. As alternativas não necessitam que o leitor reflita sobre o porquê de as pessoas apoiarem-se na oralidade para produzirem a escrita, tratando-se de uma forma que pode se apresentar como natural. Pode parecer que o escrever bem depende apenas do indivíduo, sem envolver o ensino, já que as alternativas se limitam à compreensão de ter "maior desenvoltura"; "segurança"; "o conhecimento de gêneros mais formais"; "empregar vocabulário adequado"; "utilizar recursos mais expressivos e menos desgastados da variedade padrão". Observa-se, ainda, que o anúncio não foi mencionado nas alternativas.

\section{Considerações finais}

A questão do Enem de 2009 aqui analisada esboça a força com que a indústria cultural repercute em diversas instâncias a condução do pensamento e da linguagem, portanto está ligada à formação humana na qual impera o treinamento. As formas racionalizadas do pensamento são conduzidas por um formato unidimensional, por isso, diante desse formato, interessa o leitor saber identificar o tipo de linguagem; não o conteúdo que é comunicado. A 
concepção de leitor competente proposta pelo Enem requer que se desenvolvam estratégias que o levem a ser eficiente para saber agir diante de uma situação-problema que parta da realidade familiar, ou seja, uma forma que não admite uma "certa distância diante da realidade empírica" e que, portanto, não permite a reflexão (BUENO, 2009, p. 42).

A emancipação estaria na possibilidade de um amplo movimento de as "poucas pessoas interessadas" direcionarem sua energia "para que a educação seja uma educação para a contradição e para a resistência" (ADORNO, 1995a, p. 182-183). Adorno delineia a possibilidade de resistência por meio da autorreflexão, que significa negar a vida como ela se apresenta, ou seja, a vida reificada que se impõe como essência do indivíduo. Isso vai ao encontro da afirmação de Marcuse (1973, p. 125) segundo a qual aquilo que é não pode ser verdadeiro; então é preciso olhar o que está por trás, vasculhar, "subverter" o mundo em que vivemos para entendermos o que ele realmente é. Mas a possibilidade do conhecimento não está na mera transmissão de conteúdos, “[...] cuja característica de coisa morta já foi mais do que destacada, mas [n]a produção de uma consciência verdadeira [...]" (ADORNO, 1995a, p. 141). A possibilidade está relacionada com o deixar em evidência, em primeiro momento, o que destituiu o conhecimento e também a leitura de seus princípios emancipadores.

Adorno utiliza a crítica imanente como forma de elevar a verdade; mediante as próprias palavras dos textos, realiza a crítica da linguagem. Assim, o despertar a consciência desse "leitor de mundo" significa trazer o conteúdo que está presente no texto. Qual linguagem expressa esse conteúdo? Que aspectos são necessários para o seu desvelamento? “[...] O antídoto contra a soberania ilusória do sujeito cognoscente $[\ldots]$ consiste em 'mirar além do objeto', de tal modo que, por meio de certa distância diante da realidade empírica, a realidade stricto sensu possa ser refletida" (BUENO, 2009, p. 42).

Bueno (2009) ressalta, portanto, a tensão entre o sujeito cognoscente e o objeto. Nessa relação, o sujeito incorpora e enfrenta o objeto para que, pelas mediações, o conhecimento possa se enriquecer. Ir além da imitação, com vistas a alcançar a essência da linguagem, está na compreensão dos sentidos e dos significados expressos nos textos; isso quer dizer a compreensão do conteúdo, o rigor, não apenas a identificação das diferentes formas de comunicação.

\section{REFERÊNCIAS}

ADORNO, Theodor. Educação e emancipação. 2. ed. Paz e Terra, 1995.

ADORNO, Theodor. Introdução à sociologia. São Paulo: Editora da Unesp, 2008a. 
ADORNO, Theodor. Minima Moralia: reflexões a partir da vida lesada. Tradução Gabriel Cohn. Rio de Janeiro: Beco do Azougue, 2008b.

ADORNO, Theodor; HORKHEIMER, Max. Dialética do esclarecimento: fragmentos filosóficos. Tradução: Guido Antonio de Almeida. Rio de Janeiro: Jorge Zahar, 1985.

BRASIL. Ministério da Educação. Instituto Nacional de Estudos e Pesquisas Educacionais Anísio Teixeira - INEP. Exame Nacional do Ensino Médio. Documento básico. Brasília, 2002. Disponível em: http://portal.inep.gov.br/documents/186968/484421/ENEM++Exame+Nacional+do+Ensino+M\%C3\%A9dio+documento+b\%C3\%A1sico+2002/193b6522 -cd52-4ed2-a30f-24c582ae941d?version=1.2. Acesso em: 12 jun. 2019.

BRASIL. Ministério da Educação. Instituto Nacional de Estudos e Pesquisas Educacionais Anísio Teixeira - INEP. Prova de linguagens, códigos e suas tecnologias - Enem, 2009. (Caderno 7 Azul, 2. dia). Disponível em:

http://download.inep.gov.br/educacao_basica/enem/downloads/2009/dia2_caderno7.pdf. Acesso em: 12 jun. 2019.

BRASIL. Ministério da Educação. Instituto Nacional de Estudos e Pesquisas Educacionais Anísio Teixeira - INEP. Relatório pedagógico ENEM 2009-2010. Brasília: INEP, 2013. Disponível em: http://portal.inep.gov.br/web/guest/relatorios-pedagogicos. Acesso em: 12 jun. 2019.

BUENO, Sinésio Ferraz. Da dialética do esclarecimento à dialética da educação. Revista Educação, Coleção Especial: Biblioteca do Professor, Adorno pensa a Educação. São Paulo: Segmento, ano 2, n. 10, p. 36-45, 2009.

GALUCH, Maria Terezinha Bellanda; CROCHÍCK, José Leon. Formação cultural, ensino, aprendizagem e livro didático para os anos iniciais do ensino fundamental. Maringá: Eduem, 2018.

HORKHEIMER, Max. Eclipse da razão. São Paulo: Centauro, 2002.

MARCUSE, Herbert. A Ideologia da sociedade industrial. O homem unidimensional. Rio de Janeiro. Zahar, 1973.

MARCUSE, Herbert. Algumas implicações sociais da tecnologia moderna. In: MARCUSE, Herbert. Tecnologia, gerra e fascimo. São Paulo: Editora da Unesp, p. 73-104, 1999.

MARCUSE, Herbert. Cultura e psicanálise. Tradução: Wolfgang Leo Maar, Robespierre de Oliveira, Isabel Loureiro. São Paulo: Paz e Terra, 2001.

MURRIE, Zuleika de Felice. A área de Linguagens e Códigos e suas Tecnologias no Enem. In: Ministério da Educação/Instituto Nacional de Estudos e Pesquisas Educacionais Anísio Teixeira. Exame Nacional do Ensino Médio (ENEM): fundamentação teóricometodológica. Brasília: MEC/INEP, p. 57-59, 2005. 


\section{Como referenciar este artigo}

SANTA BÁRBARA, Rubiana Brasilio; GALUCH, Maria Terezinha Bellanda; BRAGADO, Rui Sousa. Avaliação nacional do ensino médio e indústria cultural: da competência leitora à crise da leitura. Revista Ibero-Americana de Estudos em Educação, Araraquara, v. 14, n. esp. $\quad 4$, p. 1944-1959, dez., 2019. E-ISSN: 1982-5587. DOI: https://doi.org/10.21723/riaee.v14iesp.4.12920

Data de submissão: $25 / 06 / 2019$

Data de aceite: $24 / 07 / 2019$

Data de publicação: 01/09/2019 